\title{
Sensibilidade antimicrobiana de amostras de Escherichia coli isoladas de leitões lactentes com diarréia
}

\section{Antimicrobial sensitivity Escherichia coli of strains isolated from suckling piglets with diarrhoea}

\author{
Benito Guimarães de Brito, ${ }^{*}$ Kelly Cristina Tagliari**
}

\begin{abstract}
Resumo
A Escherichia coli é o principal agente infeccioso envolvido nas diarréias dos leitões lactentes, sendo usada terapia através de drogas para controlar esta doença. Foram estudadas 224 cepas de Escherichia coli isoladas de leitões lactentes com diarréia em relação à sensibilidade antimicrobiana. Os resultados mostram alta resistência a três antimicrobianos (estreptomicina, sulfonamidas e tetraciclina). Gentamicina e neomicina foram os melhores antimicrobianos na inibição do crescimento de cepas de Escherichia coli, isoladas de leitões lactentes, com diarréia, no sudoeste do Paraná.
\end{abstract}

Palavras-chave: E. coli; sensibilidade aos antimicrobianos; drogas; leitões; diarréia.

\begin{abstract}
The main infectious agent responsible by suckling piglets with diarrhoea is the Escherichia coli and the therapy by drugs is used for control of this disease. The antimicrobial sensitivity of 224 strains of Escherichia coli isolated from suckling piglets with diarrhoea were studied. The results show high resistance at three drugs (streptomycin, sulfonamide and tetracycline). Gentamycin and neomycin were the best antimicrobial in the inhibition of growing of strains of Escherichia coli, isolated from suckling piglets with diarrhoea in the southwest of Paraná.
\end{abstract}

Keywords: E. coli; antimicrobial sensibility; drugs; piglets; diarrhoea.

\section{Introdução}

As diarréias são freqüentes nas criações de suínos do Paraná e provocam grandes prejuízos econômicos (Silva et al., 1998 ; Brito et al., 1999). Na maioria das vezes estas diarréias ocorrem nas primeiras semanas de vida dos leitões (Tagliari, Brito, 1998). Vários fatores de risco contribuem para a ocorrência das diarréias: ausência do vazio sanitário, variações térmicas diárias superiores a $6^{\circ} \mathrm{C}$, além de outras enfermidades intercorrentes (Silva et al., 1998 ; Brito et al., 1999). A Escherichia colié um dos principais agentes infecciosos envolvidos nas diarréias dos leitões lactentes (Fitzgerald, 1998). Estudo epidemiológico realizado no Sudoeste do Paraná por alguns autores (Brito et al., 1995), identificou a Escherichia coli como o principal agente etiológico das diarréias dos leitões lactentes. Dentre as medidas para a redução e controle desta enfermidade, encontra-se a antibioticoterapia (Glattleider, 1993). Em virtude da diversidade de comportamento da Escherichia coli frente aos antimicrobianos, principalmente pelo uso de subdoses de antibióticos e pela fácil transferência da resistência através de plasmídios entre amostras bacterianas (Boni, Sacchi, 1989), é importante o conhecimento do padrão de sensibili- dade antimicrobiana desta bactéria para uma efetiva redução do quadro clínico. Trabalhos de sensibilidade aos antibióticos têm sido realizados com resultados variáveis (Barcellos et al., 1977 ; Wilson, 1981, Martins, 1987 ; Borowski et al., 1994). O objetivo deste trabalho foi determinar a sensibilidade antimicrobiana e os principais perfis de resistência de amostras de Escherichia coli, isoladas de leitões lactentes com diarréia, da região sudoeste do Paraná.

\section{Material e métodos}

Foram estudadas 224 amostras de Escherichia coli, isoladas de 224 leitões com diarréia durante a fase de aleitamento, entre 0 a 35 dias, de 30 granjas da região Sudoeste do Paraná. As amostras foram isoladas a partir de fezes diarréicas cultivadas durante 18 horas a $37^{\circ} \mathrm{C}$ em meios de ágar sangue e ágar Mac Conkey. As culturas que apresentaram ao redor de $90 \%$ de colônias de mesma característica morfológica foram selecionadas. A identificação foi realizada através das características morfotintoriais e provas bioquímicas (Cowan, 1975). As amostras foram avaliadas quanto à resistência aos diversos antimicrobianos através da técnica de difusão do antibiótico impregnado em discos de papel-

\footnotetext{
* Departamento de Medicina Veterinária Preventiva, Centro de Ciências Agrárias, Universidade Estadual de Londrina, Caixa postal 6001, CEP 86051-970, Londrina-PR, Brasil. E-mail: bgbrito@ zipmail.com.br

** Doutoranda do Curso de Zoologia da Pontifícia Universidade Católica do Rio Grande do Sul. Av. Ipiranga, 6681, prédio 12C, CEP 90619-900, Porto Alegre-RS, Brasil.
} 
filtro descrita por Barry e Thorwsberry (1985), com modificações. Três colônias isoladas a partir do meio ágar nutriente foram cultivadas em caldo $\mathrm{BHI}$, a $37^{\circ} \mathrm{C}$ durante 24 horas, e então a cultura foi repicada para caldo $\mathrm{BHI}$ numa diluição de 1:100 e incubada a $37^{\circ} \mathrm{C}$ durante 2 horas, sendo posteriormente semeada com "swab" em ágar Müeller-Hinton, de forma a obter um crescimento confluente. Após a secagem das placas, os seguintes discos de antimicrobianos foram usados: gentamicina $(10 \mu \mathrm{g})$, neomicina $(30 \mu \mathrm{g})$, colistina $(10 \mu \mathrm{g})$, ácido nalidíxico $(30 \mu \mathrm{g})$, kanamicina $(30 \mu \mathrm{g})$, nitrofurantoína $(300 \mu \mathrm{g})$, trimetoprim+sulfamethoxazole $(25 \mu \mathrm{g})$, estreptomicina $(10 \mu \mathrm{g})$, sulfonamidas $(300 \mu \mathrm{g})$, tetraciclina $(30 \mu \mathrm{g})$ e cloranfenicol $(30 \mu \mathrm{g})$. Na Tabela 1 constam os parâmetros de interpretação utilizados para avaliação dos resultados dos halos de inibição (Barry, Thorwsberry, 1985). A seleção dos discos foi baseada no critério da disponibilidade comercial dos princípios ativos, utilizados no controle da diarréia causada por Escherichia coli.

\section{Resultados e discussão}

$\mathrm{Na}$ Tabela 1 estão os resultados dos antibiogramas realizados com as 224 amostras de Escherichia coli. Nos testes efetuados, os antimicrobianos que apresentaram melhor resultado ( $>80 \%$ de amostras sensíveis) foram gentamicina, neomicina, ácido nalidíxico, kanamicina e nitrofurantoína. Os antimicrobianos colistina, trimetoprim+sulfamethoxazole e cloranfenicol, obtiveram resultados intermediários (50 a 70\%

Tabela 1: Sensibilidade de 224 amostras de Escherichia coli isoladas de leitões lactentes com diarréia, frente aos antimicrobianos.

\begin{tabular}{lccccc}
\hline \multirow{2}{*}{ Antimicrobianos } & \multicolumn{3}{c}{$\begin{array}{c}\text { Halo de inibição de } \\
\text { crescimento }(\mathbf{m m})\end{array}$} & \multicolumn{2}{c}{$\begin{array}{c}\text { Amostras } \\
\text { sensíveis }\end{array}$} \\
\cline { 2 - 6 } & RES & INT & SENS & N 8 & $\%$ \\
\hline Gentamicina & 12 & $13-14$ & 15 & 215 & 96,0 \\
Neomicina & 12 & $13-16$ & 17 & 202 & 90,2 \\
Ácido nalidíxico & 13 & $14-18$ & 19 & 197 & 87,9 \\
Kanamicina & 13 & $14-17$ & 18 & 192 & 85,7 \\
Nitrofurantoina & 14 & $15-16$ & 17 & 191 & 85,3 \\
Colistina & 08 & $09-10$ & 11 & 152 & 67,9 \\
Trimetoprim+Sulfamethozaxole & 10 & $11-15$ & 16 & 151 & 67,4 \\
Cloranfenicol & 12 & $13-17$ & 18 & 127 & 56,7 \\
Estreptomicina & 11 & $12-14$ & 15 & 85 & 37,9 \\
Sulfonamidas & 12 & $13-16$ & 17 & 83 & 37,0 \\
Tetraciclina & 14 & $15-18$ & 19 & 59 & 26,3 \\
\hline
\end{tabular}

Res: resistente - Int: intermediário - Sens: sensível.

de amostras sensiveis), enquanto que estreptomicina, sulfonamidas e tetraciclinas foram menos efetivos $(<40 \%$ de amostras sensíveis).

As amostras de Escherichia coli isoladas de suínos no Canadá e na Bélgica (Gannon et al., 1988 ; Pohl et al., 1991 ; Dunlop et al., 1998) foram sensíveis à gentamicina, neomicina e nitrofurantoína, o que está de acordo com os dados do nosso trabalho.

Os níveis de resistência aos antimicrobianos das amostras foram altos (Figura 1), os quais coincidem com relatos de levantamentos semelhantes realizados em outros países (Liven, 1979 ; Coates, Hoopes, 1980 ; Larsen, Sogard, 1981 ; Libal, Gates, 1982).

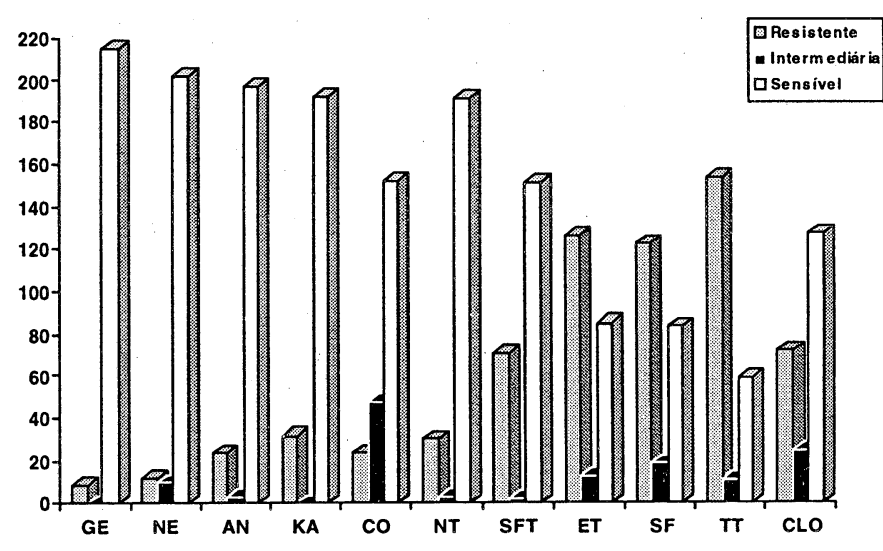

Figura 1: Comportamento das amostras de Escherichia coli isoladas de suínos com diarréia, frente aos antimicrobianos: gentamicina (GE), neomicina (NE), ácido nalidíxico (AN), kanamicina (KA), colistina (CO), nitrofurantoina (NT), trimetoprim + sulfamethoxazole (SFT), estreptomicina (ET), sulfonamidas (SF), tetraciclina (TT) e cloranfenicol (CLO).

O alto percentual de resistência à tetraciclina observado neste experimento também foi observado por vários autores (Martins, 1987 ; Borowski et al., 1994 ; Garcia et al., 1987 ; Awad-Masalmeh et al., 1992 ; Sacchi, Boni, 1989 ; Dunlop et al., 1998 ; Mathew et al., 1998), em São Paulo, Rio Grande do Sul, Venezuela, Áustria, Itália, Canadá e EUA, respectivamente. Alguns autores (Oliveira et al., 1982 ; Borowski et al., 1994), também encontraram alto percentual de amostras de Escherichia coli resistentes ao cloranfenicol e sulfonamidas oriundas de leitões com diarréia de São Paulo e do Rio Grande do Sul. A alta resistência das Escherichia coli aos antimicrobianos pode ser devida ao uso inadequado destas drogas em medicações preventivas na ração dos animais.

\section{Conclusões}

Foi observada alta resistência das amostras estudadas à estreptomicina, sulfonamidas e tetraciclina. A variabilidade de resistência encontrada entre as amostras neste estudo pode dificultar a terapêutica antimicrobiana, bem como 0 monitoramento de resistência.

Os antimicrobianos gentamicina e neomicina foram os mais eficientes na inibição do crescimento das amostras de Escherichia coli isoladas de suínos com diarréia, da região sudoeste do Paraná.

\section{Agradecimentos}

Ao Instituto Agronômico do Paraná (IAPAR), pelo financiamento do projeto. 


\section{Referências bibliográficas}

AWAD-MASALMEH, M., HINTERDORFER, F., EL HAMAKI-JELINEK, $H$. et al. Serotypes, $K_{88}$ antigen, sensitivity to colicins and to chemotherapeutics of enteropathogenic $E$. coli isolated at two Austrian investigation centres between 1988 and 1990. CONGRESS INTERNATIONAL PIG VETERINARY SOCIETY, 12., 1992, Hague:IPVS, Proceedings... p. 248.

BARCELLOS, D. E. S. N., RIBEIRO, L. A. O., WARTH, W. Colibacilose suína: sensibilidade aos antibióticos de amostras patogênicas de E. coliisoladas de suínos. Bol. IPVDF, v. 4, p. 73-78, 1977.

BARRY, A. L., THORWSBERRY, C. In: LENNETE, E. N. Manual of Clinical Microbiology, 4. ed., p. 978-987, 1985.

BONI, P., SACCHI, C. L'antibiotico resistenza nella specie suina: concetti generalli. Selezione Veterinaria, v. 30, n. 4, p. 627-634, 1989.

BOROWSKI, S. M., BARCELLOS, D. E. S. N., STEPAN, A. L., OLIVEIRA, S. J. de. Sensibilidade a antimicrobianos de amostras de Escherichia coli isoladas de suínos apresentando diarréia no período pós-desmame. Arq. Fac. Vet. Univ. Fed. Rio Grande do Sul, v. 22, p. 24-30, 1994.

BRITO, B.G., FILIPPSEN, L.F., MORES, N. et al. Etiologia da diarréia de leitões lactentes em granjas suinícolas do sudoeste do Paraná. Semina, v.16, n.1, p.13-17, 1995.

BRITO, B. G., MORES, N., AMARAL, A.L., TAGLIARI, K.C. Fatores de risco no desencadeamento de diarréias pré-desmame em granjas suinícolas do Sudoeste do Paraná. Pesquisa Agropecuária Gaúcha, v. 5, n.1, p. 127-132, 1999.

COATES, S. R., HOOPES, K. H. Sensitivities of Escherichia coli isolated from bovine and porcine enteric infections to antimicrobial antibiotics. Am. J. Vet. Res., v. 141, n. 11, p. 1882-1883, 1980.

COWAN, S. T. Cowan and Steel's Manual for the Identification of Medical Bacteria. 2. ed. Cambridge : Cambridge University Press, 1975.

DUNLOP, R.H., McEWEN, S.A., MEEK, A.H., BLACK, W.D., FRIENDSHIP, R.M., CLARKE, R.C. Prevalences of resistance to seven antimicrobials among fecal Escherichia coli of swine on thirty-four farrow-to-finish farms in Ontario, Canada. Preventive Veterinary Medicine, v. 34, p. 265-282, 1998.

FITZGERALD, G.R., BARKER, T., WELTER, C.J. Diarrhoea in young pigs: comparing the incidence of the five most common infections agents. Veterinary Medicine, v. 83, n. 1, p. 80-86, 1988.

GANNON, V. P. J., GYLES, C.L., FRIENDSHIP, R. W. Characteristics of verotoxigenic Escherichia coli from pigs. Canadian Journal of Veterinary Research, v. 52, p. 331-337, 1988.
GARCIA, D., CAVAZZA, M. E., BOTERO, L. et al. Preliminary characterization of Escherichia coli isolated from pigs with diarrhoea in Venezuela. Vet. Microbiol., v. 13, p. 47-56, 1987.

GLATTLEIDER, D. L. Pathologie digestive du porc en croissance et alimentation. Rec. Med. Vet., v.169, n. 8/9, p.719-732, 1993.

LARSEN, J. L.; SOGARD, H. The susceptibility of enteropathogenic porcine Escherichia coli strains to polymixin and other antibiotics. Nord. Vet. Med., v. 33, p. 393-402, 1981.

LIBAL, M.; GATES, C. E. Antimicrobial resistance in Escherichia coli strains isolated from pigs with diarrhoea. Journal of American Veterinary Medical Association, v. 180, n. 83, p. 908-909, 1982.

LIVEN, E. Drug resistance in strains of Escherichia coli from the intestinal tract of pigs in Norway. Acta Vet. Scand., v. 20, p. 258269, 1979.

MATHEW, A.G., UPCHURCH, W.G., CHATTIN, S.E. Incidence of antibiotic resistance in fecal Escherichia coli isolated from commercial swine farms. J. Anim. Sci., v. 76, p. 429-434, 1998.

OLIVEIRA, M.S., CASTRO, A.F.P. de, SERAFIM, M.B., PORTUGAL, M.A.S.C. Produção de enterotoxinas e resistência a drogas em colibacilos isolados de suínos com diarréia. Rev. Microbiol., v. 13, n. 2, p. 135-142, 1982.

MARTINS, M. F. Caracterização e aspectos genéticos em amostras de Escherichia coli de origem suína. 1987.147 p. Tese (Mestrado) - ESALQ-USP, Piracicaba - SP.

POHL, P., VERLINDEN, M., LINTERMANS, P., Van ROBAEYS, G., STOCKMANS, F. Antibiogrammes des entérobactéries pathogènes pour les animaux d'élevage et les pigeons, isolées en Belgique de 1996 à 1990. Annales de Médecine Vétérinaire, v. 135, p. 101-108, 1991.

SACCHI, C., BONI, P. L'antibiotico-resistenza nella specie suina: verifica della situazione nella pratica. Selezione Veterinaria, v. 30, n. 4 , p. 635-638, 1989.

SILVA, C. A., BRITO, B. G., MORES, N., AMARAL, A.L. Fatores de risco relacionados com o desempenho de leitões lactentes em granjas de suínos da região Norte do Paraná. Ciência Rural, v. 28, n. 4, p. 677-681, 1998.

TAGLIARI, K.C., BRITO, B.G. Redução do ganho de peso e ocorrência de mortalidade por diarréia em leitões lactentes. Pesquisa Agropecuária Gaúcha, v. 4, n. 2, p. 211-213, 1998.

WILSON, M. R. Enteric colibacillosis. In: LEMAN, A. D. et al. Diseases of swine, 5. ed. lowa : State University Press, EUA, 1981, p. 471-477. 